\title{
Editorial Cartoons as Mirror of the Nigerian Nation: The Example of New Telegraph
}

\author{
Dr. Ogazie, Charles Ahamuefule \\ Department of Theatre and Creative Arts, Adeyemi College of Education, Ondo, Nigeria \\ ogazieca@aceondo.edu.ng \\ Odetade, Ibitayo Odekunle \\ Department of English, Adeyemi College of Education, Ondo, Nigeria \\ odetadeibitayo@gmail.com
}

DOI: http://doi.org/10.36892/ijlls.v2i2.259

\begin{tabular}{|c|c|}
\hline $\begin{array}{l}\text { Received: } \\
\text { 30/05/2020 }\end{array}$ & $\begin{array}{l}\text { Abstract } \\
\text { Newspapers do not just report news or educate people on the happenings; it }\end{array}$ \\
\hline $\begin{array}{l}\text { Accepted: } \\
\text { 05/06/2020 }\end{array}$ & $\begin{array}{l}\text { however, serves as a watch dog in societies. As the press beams its search } \\
\text { light on the activities of government through its reportage, the public is made } \\
\text { to participate in the process of governance and at the same time, aligns the } \\
\text { governed to come to terms with the state of the nation. In a pluralistic nation }\end{array}$ \\
\hline $\begin{array}{l}\text { Keywords: } \\
\text { Editorial Cartoons; } \\
\text { Nigerian Nation; } \\
\text { National Issues; } \\
\text { Pluralistic Nation; } \\
\text { National Mirror }\end{array}$ & $\begin{array}{l}\text { like Nigeria where the heterogeneous populace is exposed to diverse media } \\
\text { content, senders of information, especially those of the print media, convey } \\
\text { socio-political, economic, educational coupled with religious messages in a } \\
\text { unique, blunt, creative but satirical manner without naming names. This paper } \\
\text { asserts that this unique function is best left at the door step of the editorial } \\
\text { cartoonists who, through their metaphorical codification sketches, drawings } \\
\text { or impressions, tell a verisimilitude tale of the state of the nation. Through } \\
\text { content analysis of selected cartoons in New Telegraph Newspaper, the paper } \\
\text { concludes that editorial cartoons can be seen as a powerful reflective medium } \\
\text { via which national issues are raised in an imaginary court for public debate } \\
\text { and erect a positive signpost towards reconstructing and sustaining the polity } \\
\text { for the betterment of all. }\end{array}$ \\
\hline
\end{tabular}

\section{INTRODUCTION}

Cartoons are basically seen as humorous drawings or pictorial sketches which are usually published in newspapers, magazines or periodicals. Before the introduction of the term 'cartoon' in its modern sense in the nineteenth century, satirical and humorous drawings of all kinds were referred to as caricatures (Nyoni, Grand \& Nyoni, 2012, p. 180). Today the term 'caricature' is used mainly to refer to distorted portraiture that emphasizes the characteristic traits of an individual or institution.

The term 'cartoon' has also been applied to comics, television and film animation, multi-frame jokes published in newspapers, continuity strips and graphic novels, humorous book, magazine illustrations and satirical puppetry. 'Cartoon' in its modern sense was first used in Punch magazine in 1843 when it applied the term to satirical drawings in its pages (Nyoni et al., 2012, p. 180).

Nigeria, a West African sub-regional country is said to have a population of over 200 million people who are blessed with a geographical space that is rich for all kinds of agricultural businesses cum economic activities (Akinyemi \& Isiugo-Abanihe, 2014, p. 342). Gaining its independence in 1960 from the British, Nigeria inherited English language as its lingua franca. It is also the language of the media and necessarily the language of cartoons. 
To the large Nigerian society, editorial cartoons are no more to be divorced from, or trusted than, the colonialists who introduced them.

In fact, as a result of one of their potency through exaggeration, they tend to be seen as quite instigative. In modern times, for instance, cartoons are used in many books on different subjects such as Sociology, Psychology, Psycholinguistics, Communication, Advertising and History to spice up the otherwise dry facts, provide more meanings and insights into certain discourse areas. Cartoons also make complex or abstract phenomenon more clear, explanatory and easy to understand (Ogazie, 2017, p.102).

In the print media, newspaper cartoons, as they are fondly called, have continuously displayed sequences of drawings arranged in interrelated panels to display brief humour or form a narration. These are often serialized with text in balloons and captions. This unique literature of change has brought about names such as "political cartoon", "newspaper stripes", "editorial cartoons" or "comics" when it is being described. One obvious thing is the fact that newspaper cartoons have the ability to educate media audience in a multifaceted manner. No wonder, Adejuwon and Alimi (2011) posit that the pedagogical function of cartoon has proven a valuable instrument and avenue to educate the readers in any publication where it appears (p.62). They believe that since it is sometimes satirical and humorous in subject, it can inevitably elicit readers' participation.

Nigeria, as many other countries of the world has several newspapers which fall under different categories. This print publication is issued at regular intervals over time. Historically, newspapers are usually issued daily or weekly, but sometimes semi-weekly (twice a week), bi-weekly (every two weeks), or monthly. One of the newspapers that are published daily in Nigeria is The New Telegraph. It is an all national newspaper with a circulation of up to a hundred thousand copies per day. The New Telegraph targets Nigerian and foreign readers in and around the country's urban centres, as well as internationally, and aims to provide objective and incisive coverage of pressing political and socio-cultural issues. Hence, the reason for its preference for this study.

\section{LITERATURE REVIEW}

\section{Editorial Cartooning: The Nigerian Example}

Over the years in the traditional Nigerian society, satire has been found in verbal and visual elements which include mask wearing, abusive and mocking songs during traditional festival by the masquerades (Jimoh, 2010, p. 17). However, in the present day, newspaper cartoons perform the same role played by the traditional caricature or satire.

Editorial comics in Nigeria can be traced to the tail end of the colonial rule around 1944 when Nnamdi Azikiwe's West African Pilot engaged the services of Akinola Lasekan, essentially a commercial artist and painter known as "LASH," to draw editorial cartoons. His acerbic attacks on the then colonial government often attracted the attention and fury of that government which, times without counts, threw him into jail (Jimoh, 2010, p. 22).

This innovative move by Lasekan set the tone of radicalism among other artists who came after him; so deep was his impact that his children followed his footsteps. One of his sons was said to have drawn, in the 1970s and 1980s, the now discontinued "Benbella" for The Daily Times." Other newspapers followed the innovative and provocative technique of the cartoon prints of the West African Pilot by engaging the services of artists to illustrate editorials or submit materials for editorial cartoons. However, The Daily Times under Babatunde Jose took cartooning to a greater height when it built a stable of gifted and talented artists, such as Dele Jegede, Josy Ajiboye, and David Akande, who studied commercial art under Lasekan (Onipede, 2007, p. 2; Adejuwon and Alimi, 2011, p. 62).

Lasekan's and Akintola's cartoons were not as sophisticated as the type we have in today's dailies. Study shows that cartoons were carved on a woodblock (Jegede, 1991, p. 6). 
Apparently, this means that the text and illustrations materials were carved by hand using wood blocks (Redmond, 2009, p. 2). This discouraged creativity because of its tedious nature as captions were all carved painstakingly and rigidly. Even at this, he took cartooning as one of the ways of making his feelings known towards the policies of the ruling government of that time; hence, he became very committed to the art.

By implication, cartoons became viable amalgams of images (the symbols), captions (the written words), and social commentary (the spoken and unspoken words through which socio-political and economic issues are discussed) used to correct all anomalies in the society (Adejuwon \& Alimi, 2011, p. 5). Study reveals that about six decades ago, cartooning was not popular as it was limited to papers whose publishers were aware of its joys in foreign countries (p.6). These cartoons were well domesticated with relevant information which the local audience interpreted appropriately. The sketches were sandwiched with useful imageries, metaphors, symbolisms and other rhetorical devices that lampooned the reality of that time. Socio-political and economic commentators also effectively used its potency to satirize unwanted behaviours of the ruling class while at the same time used it to ventilate public opinions without being confrontational (Jimoh, 2010, p.23).

From its inception, therefore, the editorial cartoon has been seen to stand in a gap between the ruled and the rulers as a potent reflective mirror in a pluralistic and complex society like Nigeria where social issues are boldly commented without fear. Through selected editorial cartoons from New Telegraph, this paper raises socio-political and economic issues in an imaginary balance of social justice for public debate with a view of summoning both the government and the governed to a common forum for public discussion towards reconstructing the polity for a sustainable development.

\section{Theoretical Consideration}

Since the main thrust of this paper is to explain how editorial or newspaper cartoons mirrors or reflects socio-political realities in Nigerian society through its metaphorical codification sketches or drawings, I am faced with the task of explaining how editorial cartoons serve as competent watch dog on the activities of government through its reportage. The theoretical consideration for this study would be based on Agenda Setting theory.

The mass media as the Fourth Estate of the Realm are changed with the duty of holding government accountable to society. This is accomplished by reporting the various activities and events as they emanate from society through a creative but satirical way. As conveyors of information playing up an issue will lead to public discourse and more importance attached to it. McCombs and Shaw in their Chapter Hill Study in 1968 developed the Agenda Setting Theory. This theory explains that the mass media which the editorial is an integral part, in their reportage, do set up the agenda for public opinion by highlighting certain issues for public debate. Cohen (1963), as cited in Daramola (2003), believes that the press generally may not be successful much of the time in telling people what to think, but they are stunningly successful in telling them what to think about (p.85).

This power attributed to the media generally and the editorial in our example cannot be wished with mere wave of hand as there is popular saying that "pen is mightier than a gun. It is against this background that editorial cartoons are seen viable and powerful reflective medium through national issues are raised for public debate in a creative and imaginary court of individual conscience particularly in Nigerian society.

\section{METHODOLOGY}

In Nigeria, one of the few dailies that may be considered national newspapers in terms of their circulation, distribution and readership is New Telegraph. This newspaper was considered above others in its category through purposive and convenience sampling. Among 
all the newspapers sampled around the stated period, only New Telegraph had consistent and relevant samples of cartoons in line with this consideration. Four editorial cartoons with relevant thematic preoccupation were purposively selected from four different volumes of New Telegraphs Newspaper in December 2017 as this period witnessed several sociopolitical and economic challenges. This study took a qualitative research design approach while data were examined through simple textual analysis.

\section{DATA ANALYSIS AND DISCUSSION}

Fig. 1 below literarily showcases an official of the Economic and Financial Crimes Commission (EFCC) who had hid himself in a room to get a glimpse of a perceived looter or fraudster. The sketch preempts that the "thief" had eventually escaped with some amount of money. It is also obvious that the undisclosed amount of money is in dollars, making readers to come to terms with the fact that there is a problem at hand. And this time, the problem is connected with financial fraud and EFCC the body empowered by law in Nigeria to go after looters.

EFCC is an anti-graft agency created by the former Nigerian President Chief Olusegun Obasanjo. The agency is saddled with the responsibility of detecting financial crimes and also arresting people found culpable in this type of crime. The agency comprises policemen that are specially trained to detect and arrest financial fraudsters and looters.

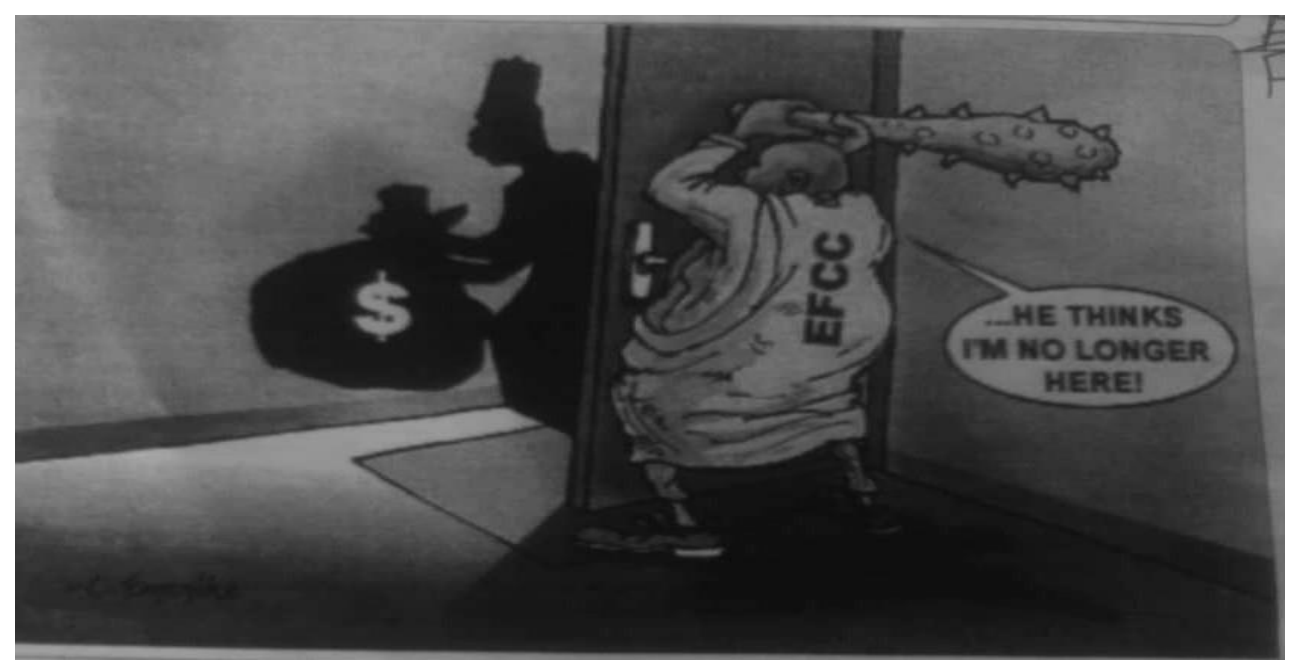

Fig 1. 'No longer here' cartoon

From the cartoon, it was discovered that the EFCC official put on an "Agbada" which is popular Nigerian attire traceable to the upper or elite class. This is opposed to the dress code of a security operative who is expected to be in smart uniform ready for combat. Before the EFCC official could stand up and chase the "perceived thief", the looter had escaped with the money through the door. The EFCC official ironically said "....He thinks I'm no longer here." From this statement, one could deduce that the EFCC official had become inactive in his operations, thus making his suspect to escape easily without being caught. This lackadaisical attitude of the EFCC official towards his duties could have been as a result of incompetence or a display of loyalty to a ruling political group which consequently resulted to selective judgment. Obviously, the "Agbada" worn by the official instead of uniform clearly speaks of the apathetic and unprofessional attitude of the EFCC official.

With the Agbada, he is portrayed a political errand boy or at worst, a social missile in comatose only active against political opponents. And as the perceived looter's identity remained hidden to the reading audience but known to the EFCC official, it is apparent that the issue of inactivity and the hidden political image is deliberate. Thus, having the 
understanding of the agency's gimmicks, the fear of being caught or hit by its baton gave the looter a leeway to escape with the stolen money through the backdoor.

This New Telegraph newspaper cartoon vividly depicts the unfortunate but reality of socio-political and economic situation in Nigeria. It shows that the Nigerian government is making concerted effort in fighting corruption through the EFCC but this "national disease" has eaten up all the essential nerves of the national heart. The reality is that the more the government is fighting the fire of this social evil called corruption, the stronger and wilder it becomes as people have devised different and sophisticated ways of siphoning national treasury without being caught. In fact, the mantras "say no to corruption" and "Change begins with me" of the present administration of President Muhammadu Buhari are ironically becoming clarion calls for more corrupt practices. Hence, the cartoon makes an emergency national call for selfless leadership, collective social responsibility and a total fight against corruption by both the ruled and rulers in Nigeria without being partisan or pitching tents of hatred through religion.

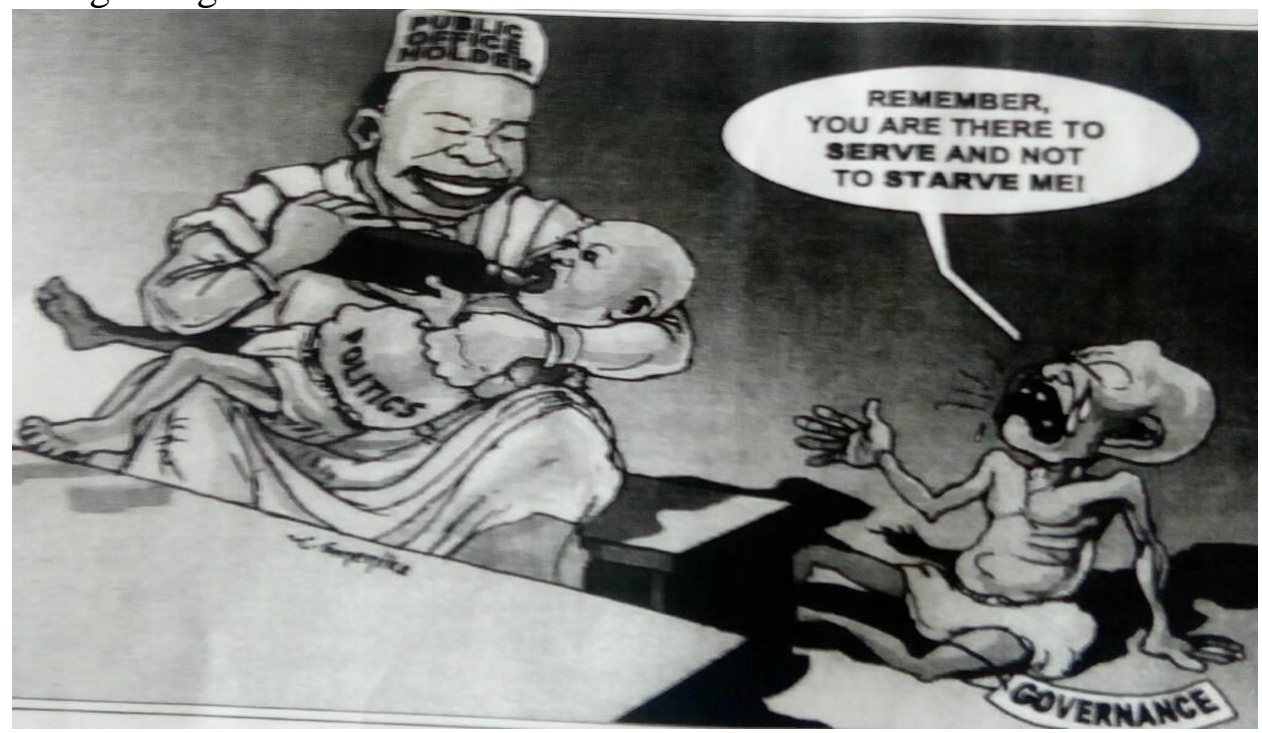

Fig. 2. 'To serve and not to starve' cartoon

One of the chief essences of holding a public office in any society is geared towards serving the interest of the people. But in recent times, reverse is the case in Nigeria and in most African countries as public office holders no longer go into politics with the intention of rendering service to the people. Instead they are concerned with propagating their selfish interest through looting of public funds.

Fig. 2 by all standards supposedly ought to have been published before Fig. 1, the reason being that the present cartoon could as well be taken to be the prologue of the previous. The cartoon on Fig. 2 hypothetically shows a public office holder who ought to be caring for the masses but unfortunately opted for the reverse. The public office holder looks well-nourished as he is also seen trying to feed his presumed "baby" obviously a member of his family with the dividends of politics and leaving the governed (masses) to starve to death through the instrumentality of bad governance. From the sketch, "politics", the man in Agbada represents every individual holding public office in Nigerian government while "governance" stands for the electorates or the masses.

As portrayed in the sketch, governance (masses) is seen crying out loud to challenge the insensitivity of the (politics) the public office holders, who at their inauguration sworn to serve and uphold public interest over that of individual. The sketch conspicuously expresses the agony of neglect which the masses continuously suffer from the hands of the political office holders. And this neglect has resulted to poor health condition, starvation and eventual death of innocent masses. The sketch ironically presents public office holders as consistently fanning the embers of politics to enrich their pulses. They are accused of constantly amassing 
wealth illegally and turning unpatriotic ears to the cries and sufferings of the masses. Most often these public office holders forget that they are in government to serve the people and not to please their purses because if there are no people, there cannot be government.

It is alarming to note the podium of politics in Nigeria is no longer that of service, it has become a platform to promoting egocentrism, violence, unemployment, selfishness and all forms of unpatriotic acts.

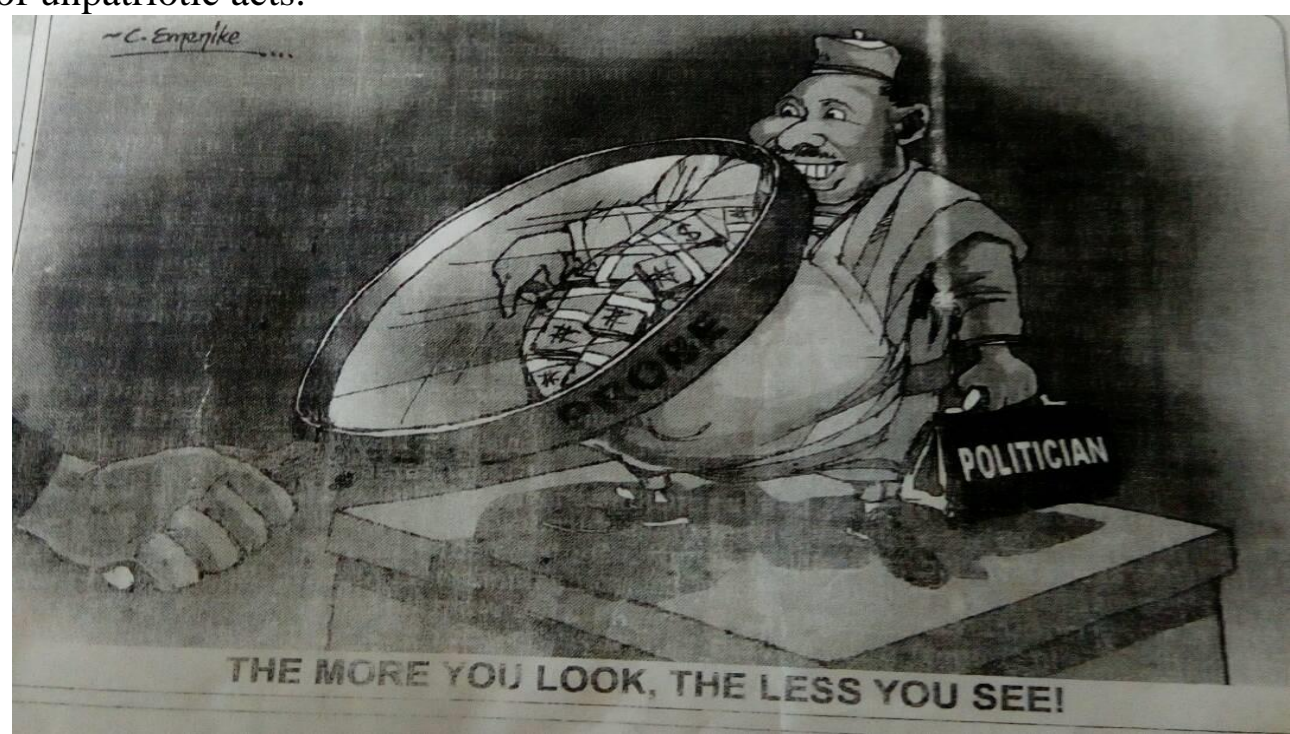

Fig. 3. 'The more you look, the less you see! cartoon

Fig. 3 above further illustrates the level of selfishness, corruption and insincerity found in Nigerian political circle. From the sketch above, it can be deduced that the fat man in Agabada attire is a Nigerian politician and his personality is further made conspicuous with the "Politician" inscription on his briefcase. This inscription gives us the notion that the man has been holding political office for a while.

The cartoon obviously shows a hand holding a magnifying lens tagged "Probe". From all indications this lens is actually meant to search the content of the politician's big tummy. The result of the X-ray shows that the politician has fully stuffed his tummy with bails of money in hard currencies. The indication is that the politician's big tummy (bank account) is full of fraudulently amassed wealth gathered in governance within a period of time.

Beneath the cartoon is another caption tagged "The More You Look, The Less You See". This caption further highlights the crafty and invisible nature of the political office holders in Nigeria. It literarily depicts the fact that the more the Nigerian anti-graft agencies try to curtail the excesses of these corrupt Nigerian political office holders, the less effective the fight against corruption becomes.

As revealed in the cartoon, the search light of the anti-graft agencies has caught up with the corrupt politician who has devised means of embezzling public funds. It is worthy of note that corrupt politicians now transfer bulk amount of looted funds into their local and foreign bank accounts or alternatively stock it underground in their houses and offices for the fear of being caught. These selfish actions of corrupt politicians now cause resultant hardship Nigerians are facing. Recently, the federal government of Nigeria released names of alleged looters of the commonwealth of the country with the hope that these fraudsters would be prosecuted, if found guilty.

Indeed, it is a paradox that Nigeria, the world's eighth largest exporter of crude oil, a country endowed with many resources, still has more than 70 percent of its population living below the poverty line as a result of corruption and mismanagement. Pathetically, the logic of the Nigerian political leadership class has been that of self-service as some of the leaders are mired in the pursuit of selfish and personal aggrandizement and self-glorification with the result that corruption has become euphemism for explaining political leadership in Nigeria in relation to the management of national wealth. 
The last editorial cartoon to be analyzed in this paper is proverbial in nature. This cartoon tends to mirror the socio-political realities of the Nigerian nation and forewarns its entire citizenry of the impending danger which may engulf the entire fabric of the polity if care is not taken. Of course, there have been various debates from divergent quarters over the collective existence of the Nigerian nation, thus this has led to the creation of a sociopolitical, economic and religious dichotomy.

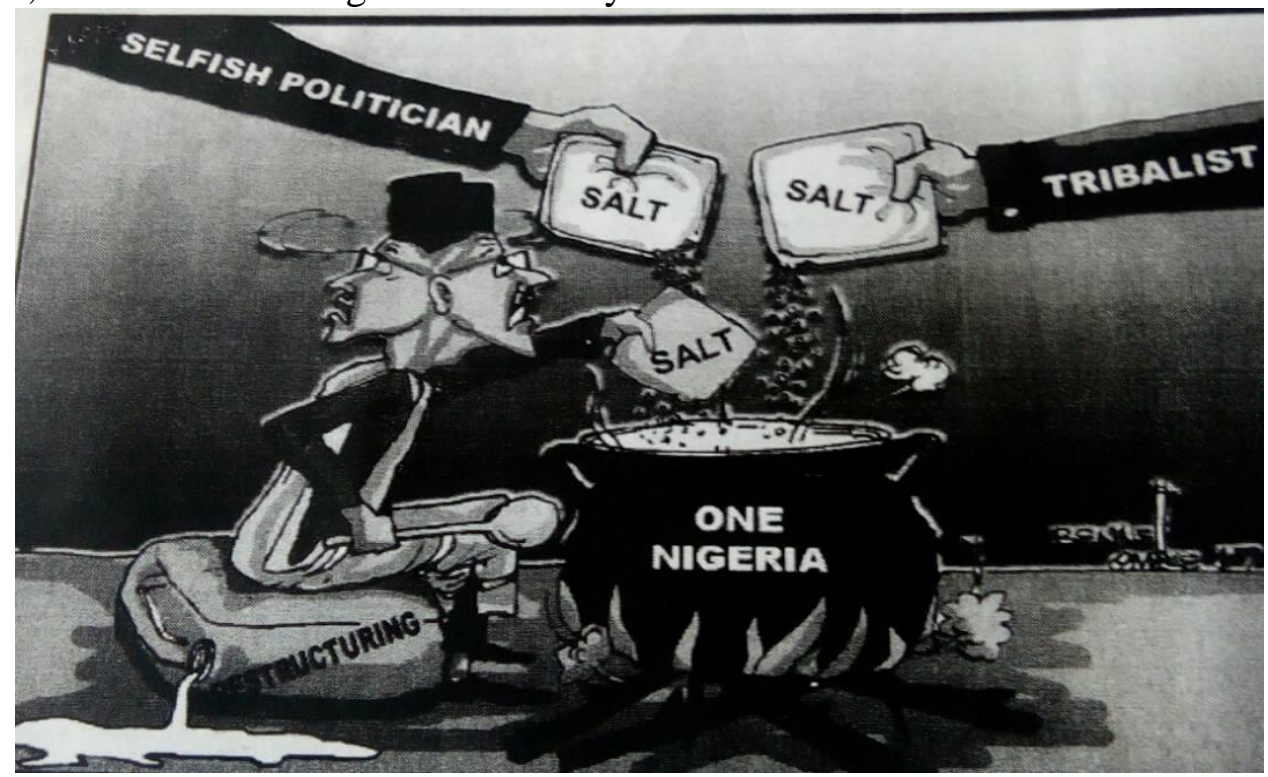

Fig. 4. 'One Nigeria' cartoon

Obviously, Nigeria is going through turbulent times because her political leaders have refused to take up the responsibility of serving the interest of the nation with deserved patriotism. And until all citizens see the Nigeria project as a common inheritance which must be preserved for posterity, it (Nigeria) may remain in perpetual bondage of backwardness.

This cartoon raises series of questions which border on the management of collective nationality and common inheritance. It showcases one big pot which represents a nation at a glance. On it is written "One Nigeria", with a foregrounded element signaling the existence of a hot debate on the entity. A man is seen sitting on a keg named "Restructuring" where a liquid like petrol keeps pouring on the floor near fire. Indeed, this looks very dangerous as that cooking environment which represents the entire Nigeria nation could be engulfed with fire if adequate care is not taken. The image in the cartoon is with two faces - one facing the pot and the other facing the opposite side. He is seen stirring the content of the pot with a spoon. The implication is that if he continues to stir the pot with all the various hands pouring salt into it, the country Nigeria may never know peace.

The British Colonial Government amalgamated the Northern and Southern Protectorates in 1914, thus initiating the creation of the Nigerian nation. The "created entity" is a combination of different nationalities with different socio-political and cultural realities. The marriage of these regions was initially celebrated but soon brought about suspicion and untold divisions among the concerned ethnic groups. This is dramatically displayed with the sighting of this big pot on fire with different hands adding excessive salt into its content. The different hands seen pouring salt into the pot includes those of "Tribalist" and "Selfish Politician."

From all indications, the One Nigeria project may never come true as the entire citizenry may never enjoy good governance as a result of national incoherence and disagreements from all aggrieved groups. And until governments at all levels in Nigeria cease to speak with both sides of their mouths on issues that bother on national unity, the One Nigerian Pot may continue to boil with its hyper-salty content, hence, making the nation worthless and a black sheep among comity of nations. 


\section{FINDINGS}

This study revealed among other things that editorial cartoons with those of The New Telegraphy in our instance are viable mirror which has the capacity to reveal socio-political realities in any country of the world especially Nigeria through its metaphorical codification sketches.

Going by the study, it was also discovered that editorial cartoonists are social watch dogs that can effectively monitor, criticize and correct governmental activities while entertaining its audience at the same time.

It was further revealed via the study that the Nigerian nation and its government can easily be placed in a court of conscience with biting issues discussed without calling names. Hence, this shows that editorial cartoon is a faithful and true "barbing blade" which can be amusedly used to shave the heads of corrupt leaders right at their presence.

Finally, the study discovered that editorial cartoons can be revolutionary in nature as the society can trust it to lead a vanguard of change in the face of tyrant governments. It was also discovered that when editorial cartoons are used to satirize corrupt governments and their inhuman socio-political policies, the society is amused and moved towards correcting the anomalies by involving themselves in critical discourse raised by the agenda through the sketches and this finally sends a signal of caution to those in authority.

\section{CONCLUSION}

From the above discussion, it has been seen that a lot of messages are embedded in editorial cartoons, a form of popular art. Popular arts have been an expressive art and it is recognized as an area of discourse which belongs to the people. In other words, popular arts like cartoons, graffiti and slangs belong to the people. The masses make meanings out of these popular arts because the messages are simply derived from their everyday experiences. The accessibility of popular arts and its engagement with socio-political issues in the society has been shown to provide a veritable means through which different shades of meanings are derived. Thus, this paper has been able to make known the fact that editorial cartoons do not just report news, make known governmental policies or educate people on the happenings in societies among other things. It serves as a watch dog in society through its exaggerated metaphoric sketches and satirized language which mirror the happenings in society.

The paper concludes that apart from amusing its audience, editorial cartoon has become a potent mirror which reflects socio-political realities of the nation and with it the society is educated and conscientized. No doubt, editorial cartoon has taken its rightful place in the popular literary tradition by constantly interrogating and engaging the socio-political dynamics of the Nigeria nation and the world at large.

\section{REFERENCES}

Adejuwon, A., \& Alimi, S. (2011).Cartoon as illustration: political process in Nigeria. The Journal of Pan African Studies, 4(3). 57-76.

Akinyemi, A.I., \& Isiugo- Abanihe, U.C. (2014). Demographic dynamics and development in Nigeria: issues and perspectives. African Population Studies, 27(2), 239-248.

Daramola, I. 2003. Introduction to mass communication. Lagos: Rothan Press Ltd.

Jegede, D. (1991). Nigerian cartoonists, sleeping with one eye open in Tunji, O. (Ed.) Media, transition and Nigeria. Lagos: Tosen Consult.

Jimoh, G.B. (2010). The role of editorial cartoons in the democratisation process in Nigeria: a study of selected works of three Nigerian cartoonists. M.A. Thesis, Department of Creative Arts. University of Lagos 
Nyoni, M., Grand, N., \& Nyoni, T.(2012). Beyond the humour: a newspaper cartoon as sociopolitical-economic commentary: the case of 'Wasu' of the Manica post in Zimbabwe. Greener Journal of Social Science, 2(6), 179-190.

Ogazie, C.A. (2017). Perception of animated television commercials by viewers in Southwestern Nigeria. Ph.D Thesis, Department of Theatre Arts. University of Ibadan.

Onipede, A. (2007). Cartooning in Nigeria: a brief outline: an exhibition of commemorative cartoons. Lagos State at 40: Lagos State Council of Arts and Culture. 34-45.

Redmond, W.A. (2009). Woodblock. Retrieved from Encarta Microsoft.

Primary Data Source

Cartoon One: New Telegraph - 19/12/2017 - Page 15

Cartoon Two:New Telegraph -11/12/2017 - Page 15

Cartoon Three: Sunday Telegraph - 17/12/2017 - Page 7

Cartoon Four: New Tele 